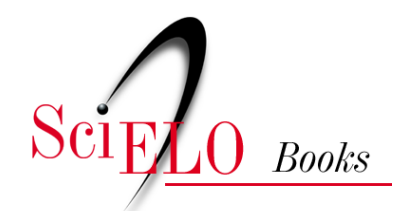

\title{
Conferência \\ Políticas públicas no contexto da crise do estado de direito
}

\author{
Aldo Fornazieri
}

\section{SciELO Books / SciELO Livros / SciELO Libros}

FORNAZIERI, A. Políticas públicas no contexto da crise do estado de direito. In: BARROS, S., BATISTA, L.E., and SANTOS, J.C., comps. Saúde mental e reabilitação psicossocial: avanços e desafios nos 15 anos da Lei 10.2016 [online]. Uberlândia: Navegando Publicações, 2019, pp. 113-124. ISBN: 978-6581417-07-9. https://doi.org/10.7476/9786581417079.0007. Transcrição dos Anais do II Encontro de Saúde Mental - Reabilitação Psicossocial: avanços e desafios 15 anos após a Lei 10.216, Uberlândia, MG, 2016.

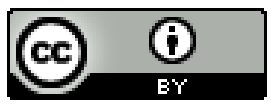

All the contents of this work, except where otherwise noted, is licensed under a Creative Commons Attribution 4.0 International license.

Todo o conteúdo deste trabalho, exceto quando houver ressalva, é publicado sob a licença Creative Commons Atribição 4.0.

Todo el contenido de esta obra, excepto donde se indique lo contrario, está bajo licencia de la licencia $\underline{\text { Creative }}$ Commons Reconocimento 4.0 . 


\section{Conferência - Políticas públicas no contexto da crise do estado de direito}

Coordenação: Prof.a Dra ${ }^{a}$. Ana Luísa Aranha e Silva - Enfermeira, Professor Doutor Associado do Departamento de Enfermagem Materno-Infantil e Psiquiátrica da Escola de Enfermagem da USP.

\section{Prof. Dr. Aldo Fornazieri}

Físico, Doutor em Ciência Política, Professor da Fundação Escola de Sociologia e Política de São Paulo (FESPSP), Diretor Acadêmico da FESPSP, Coordenador do curso de pós-graduação Globalização e Cultura da FESPSP.

Eu quero agradecer à professora Sonia Barros por ter me convidado para este evento. Quero agradecer também à professora Ana Luiza e dizer que para mim é uma honra estar aqui com vocês, na medida em que eu entendo que este movimento é um movimento fundamental para o país, principalmente pelo seu conteúdo humanístico, porque eu acho que a característica fundamental deste movimento aqui é o seu conteúdo humanístico.

E nós, que trabalhamos com ciência política, com filosofia política, entendemos que precisamos nos juntar para um processo civilizatório, principalmente tendo em vista os acontecimentos do mundo de hoje, que não são nada animadores, digamos assim. Então, desde que a vida política, a própria noção de política nasceu lá com os gregos antigos, a ideia da polis, que significava, numa tradução mais ou menos aproximada significava cidade, a polis significava a vida em comum. E hoje em dia o que nós vemos nos Estados, nos países é que essa ideia da vida comum, do interesse comum, do bem comum é uma ideia extremamente fragilizada.

Nós vivemos uma era de individualismo extremo, de desconstituição de políticas públicas, de agravamento das desigualdades. Então, com movimentos desumanizadores, como nós vimos o que está acontecendo na Europa com os refugiados, com os imigrantes e, num certo sentido, também a vitória do Trump nos Estados Unidos tem um conteúdo, um movimento, um fluxo de desumanização, quer dizer, a ideia de construir um muro num mundo globalizado. Então, de fato vivemos um momento de bastante 
perplexidade. Então, parabéns a todos por participarem deste movimento, principalmente pelo seu conteúdo. Bom, eu fui convidado para falar sobre as Políticas Públicas num Contexto de Crise do Estado de Direito, então eu fiz um pequeno roteiro para falar sobre esse assunto e esse roteiro, digamos assim, comporta tentar talvez esclarecer um pouco o que significam esses conceitos que estão propostos. Em primeiro lugar o conceito de política pública. Certamente, vocês têm uma noção do que são políticas públicas, mas eu vou tentar esclarecer um pouco mais esse conceito de política pública. Em segundo lugar, o que é o Estado de direito, quer dizer, no mundo se fala muito em Estado de direito, mas muitas vezes não se tem noção do que seja o Estado de direito. E em terceiro lugar, o que é a crise do Estado de direito, exatamente o tema que foi proposto. Bom, políticas públicas, na verdade, quando se fala em políticas públicas, nós falamos numa coisa relativamente recente na história da humanidade.

Podemos dizer que as políticas públicas começaram a aparecer no final do século 19. Nos livros de história de políticas, e política pública normalmente é relacionada também à noção de social, de Estado social, de política social, elas apareceram basicamente na Prússia, entre 1883 e 1875, sob o governo de Bismarck na Prússia, que é a região mais ou menos que abrange a Alemanha, a Áustria e assim por diante, quando começaram a acontecer greves de operários e naquele momento Bismarck editou leis chamadas leis antissocialistas. Essas leis tinham um caráter fundamentalmente ambíguo, porque, por um lado, proibiam a manifestação política e greve de trabalhadores, mas, por outro lado, tinham um conteúdo fortemente social, porque ele começou a instituir a ideia da redução da jornada de trabalho. Os trabalhadores trabalhavam 15, 16 horas, introduziu a ideia de uma remuneração mais ou menos fixa, introduziu a ideia de descanso semanal e também essa lei incidiu, de certa forma, sobre os aluguéis. Então pela primeira vez, aparentemente, na história, um governo começa a instituir políticas públicas que têm uma natureza social.

Aqui no Brasil, essa discussão também surgiu nessa mesma época mais ou menos. Vocês sabem que a República foi proclamada em 1889 e nesse contexto da Proclamação da República aconteceu uma Constituinte que fez a Constituição Republicana e, naquele momento, se constituiu um grupo particularmente ligado à doutrina positivista do sociólogo francês Auguste Comte. E era um grupo que se organizava fundamentalmente no Rio Grande do Sul em torno de um líder republicano lá que se chamava Júlio de Castilhos. E no Rio de Janeiro tinha um grupo também positivista que era ligado ao Apostolado Positivista, que eles de certa forma misturavam as teorias do Comte com uma espécie de religiosidade. E esse grupo apresentou na Constituinte um programa social, um dos mais 
avançados do mundo e, na nossa historiografia brasileira, praticamente desconhecemos esse fato. Então toda a ideia do salário-mínimo, de limitação do tempo de trabalho, da jornada de trabalho, a questão de benefícios, de saúde e assim por diante estavam naquele projeto que foi apresentado na Constituinte no final do século 19.

Não por acaso, depois dos anos 30, quando aconteceu a revolução de 1930, Getúlio Vargas instituiu, digamos assim, um programa de direitos. E, equivocadamente, normalmente se diz que Getúlio Vargas copiou esse programa de direitos que instituiu direitos trabalhistas, a CLT e assim por diante, ele teria copiado isso da Carta del Lavoro, do Mussolini, na Itália. Na verdade, é um equívoco, porque Getúlio Vargas se criou politicamente, se formou politicamente nesse contexto do positivismo liderado pelo Júlio de Castilhos no Rio Grande do Sul. Tanto é que quando morre Júlio de Castilhos, se não me engano, em torno de 1901, por aí, Getúlio Vargas era jovem, estudante de direito e ele fez o discurso fúnebre do Júlio de Castilhos. Então Getúlio Vargas já conhecia, ainda na sua juventude, todo esse contexto do conhecimento da ideia de políticas públicas e políticas sociais e assim por diante. Então ele simplesmente não copiou Mussolini, mas ele já tinha essa doutrina dos chamados direitos sociais.

Mas como é que nós poderíamos definir teoricamente a ideia de políticas públicas?

As políticas públicas, normalmente, implicam numa ação positiva do Estado. $\mathrm{O}$ que é uma ação positiva do Estado? O Estado tem que agir, tem que ser pró-ativo para que existam políticas públicas. Não existem políticas públicas sem uma pró-atividade do Estado. Então esse é o conceito básico: não há políticas públicas sem uma ação positiva do Estado. Essa ação positiva do Estado pode ser demandada simplesmente do governante, ou ela pode passar por um processo de aprovação de uma lei que institui a política pública mediante os representantes do povo, que são os parlamentares e assim por diante. E o que visam atender, qual é o objetivo de uma política pública? O objetivo de uma política pública é atender determinados carecimentos da sociedade, determinadas necessidades da sociedade.

Então, por exemplo, vocês trabalham aqui com saúde mental e tem pessoas que demandam serviços de saúde mental. Então, essas pessoas que demandam serviços de saúde mental são portadoras de determinados carecimentos. Assim como a educação é um carecimento, ou outras esferas do direito social são carecimentos e toda política pública visa atender, fundamentalmente, carecimentos humanos. E por que se faz a política pública? Porque se reconhece que as pessoas, por si sós, no contexto do mercado, das relações do mercado, não são capazes de dar conta dos seus carecimentos. Então o processo histórico vai estabelecendo o reconhecimento de que é um care- 
cimento fundamental e que aspessoas são portadoras de um carecimento fundamental que merece ser protegido publicamente. Esses carecimentos têm fundamentalmente duas dimensões, uma dimensão de curto prazo ou uma dimensão de longo prazo. Por exemplo, quando uma pessoa fica desempregada e precisa do salário-desemprego é um carecimento de curto prazo. Uma pessoa portadora de necessidades demandadas, por exemplo, isso que vocês trabalham aqui, que é a saúde mental, é um carecimento de longo prazo, portanto ela é portadora de uma necessidade permanente de proteção. A licença-maternidade é um carecimento de curto prazo, uma pessoa que fica inválida por conta de um acidente tem um carecimento de longo prazo. Então, os carecimentos têm, basicamente, essa dupla conformação: carecimentos de curto prazo e carecimentos de longo prazo. E as políticas públicas, normalmente, se definem em função do tipo de carecimento. Bom, as políticas públicas então são orientadas para atender essas necessidades e, normalmente, essas necessidades são reconhecidas como direitos das pessoas. E essa ideia de direitos surge exatamente no trânsito do século 19 para o século 20. Como é que era feito anteriormente, digamos assim, esse atendimento a determinados carecimentos? Eles eram feitos a partir daquilo que se chamava, digamos assim, assistência que não reconhecia os direitos, era caridade.

No século 19 se praticava, fundamentalmente, a caridade. A partir do início do século 20, esses carecimentos passam a ser reconhecidos como direitos das pessoas. $\mathrm{E}$ essa ideia de que os carecimentos são direitos se firmou, principalmente, no entre guerras. Vocês sabem que em 1930, por aí, ocorreu uma crise mundial, a chamada Grande Depressão, com milhões de pessoas empobrecidas, desempregadas e assim por diante. E tanto na Europa quanto nos Estados Unidos, principalmente, começaram a surgir políticas públicas para garantir direitos. E no contexto do final da Segunda Guerra Mundial surgiu na Europa aquilo que se chama Estado do bem-estar social. Esse Estado do bem-estar social vai constituir direitos não mais entendidos como caridade, mas exatamente como direitos das pessoas. Esses carecimentos passam a ser entendidos como direitos.

Como é que se instituem as políticas públicas?

As políticas públicas têm alguns atores fundamentais para que elas se formem. Em primeiro lugar é o movimento das próprias pessoas portadoras de carecimentos. Então, no mundo do trabalho, no mundo da educação, no mundo da saúde e assim por diante, ocorreram lutas e essas lutas demandaram proteção do Estado. Uma outra forma pela qual se instituem políticas públicas é através da disputa político- partidária, quer dizer, os partidos precisam ganhar votos para ascender ao poder e nesse sentido também passaram propor políticas públicas, por exemplo, na Europa surgiram os chamados 
partidos socialistas, social-democratas e eles defenderam políticas públicas para que elas fossem aprovadas nos parlamentos europeus. O terceiro ator importante da formulação de políticas públicas surge dentro do próprio Estado, a burocracia estatal. Tendo em vista que a burocracia estatal tem um interesse também na expansão do Estado, ela também passou a formular, a teorizar e a propor políticas públicas. Então, de modo geral, nós temos esses três grandes atores no processo de constituição de políticas públicas. Em primeiro lugar, os movimentos trabalhistas e sociais, por exemplo, o movimento social como o de vocês, que vai fazer demandas para o Estado. Em segundo lugar, os partidos políticos e em terceiro lugar a própriaburocracia estatal. Então se tem que, normalmente, esses três atores são, digamos assim, formuladores das políticas públicas.

Qual é o caráter de uma política pública?

Quer dizer, então ela visa atender, fundamentalmente, carecimentos humanos, mas o seu caráter é distributivo ou redistributivo. Por que ela tem um caráter distributivo ou redistributivo? Porque para atender a maioria das políticas públicas se requer recursos e, convenhamos, você não vai tirar recursos daquele que é portador do carecimento para devolver o recurso a essa mesma pessoa que é portadora de carecimentos. Então a política pública, de modo geral, tem essa natureza distributiva, redistributiva e o processo distributivo ou redistributivo se dá, fundamentalmente, pela via dos impostos. Quer dizer, os impostos têm que ter um caráter progressivo, o que significa que você vai tirar de quem tem mais para dar para aqueles que são portadores de carecimentos, para aqueles que têm menos. E aqui eu queria fazer uma pequena nota nisso, porque essa ideia do caráter distributivo ou redistributivo da política pública, fundamentalmente, na Europa veio a ser conhecida como Estado do bem-estar social. Só que aqui no Brasil nós temos uma enorme perversidade e ela se dá, digamos assim, no caráter regressivo do nosso sistema tributário.

O que se faz aqui no Brasil, você tira de quem tem menos para dar a quem tem mais, quer dizer, todo mundo que estuda o sistema tributário do Brasil sabe disso, quer dizer, tira-se de quem tem menos para dar para quem tem mais. E muitas vezes os próprios movimentos sociais, movimentos corporativos patrocinam políticas elitistas, por incrível que pareça. Por exemplo, quando se demanda a ideia de que as universidades públicas têm que ser públicas e gratuitas para todos, você também está instituindo privilégios, porque quem estuda em universidade pública normalmente é gente rica, gente que tem dinheiro e assim por diante. Então, vejam o seguinte, eu sou a favor do ensino gratuito na universidade pública, mas para aqueles que são portadores de carecimento e não para todo mundo, acho que a pessoa que tem condições deveria pagar e assim 
por diante. E mesmo no setor público, o que nós vemos são muitos privilégios, inclusive defendidos pelos movimentos sindicais, pelos partidos políticos de esquerda e assim por diante. Então, esta é uma perversidade que tem no Brasil e isso tudo deveria serdiscutido.

Bom, mas voltando à questão das políticas públicas, podemos dizer que nós temos, digamos assim, dois tipos, ou duas, ou três, ou quatro tipologias de políticas públicas. Temos as políticas públicas estruturantes e as políticas públicas compensatórias, de um lado. O que é uma política pública estruturante? Por exemplo, uma política pública de educação e saúde e assim por diante é uma política pública estruturante, porque ela, digamos assim, cria insumos para a melhoria permanente da sociedade. Então ela, digamos assim, é uma política pública que muda a qualidade da sociedade. E temos políticas públicas compensatórias. Podemos dizer que o Bolsa-Família, por exemplo, é uma política pública compensatória, por quê? Embora ela tenha um elemento estruturante, eu vou falar porque. O Bolsa-Família demanda alguns requisitos e é compensatório, porque visa solucionar um problema que é temporário, que aquela pessoa está na pobreza, numa condição de pobreza, ela tem filhos pequenos e assim por diante, então é uma compensação, ou o próprio Prouni é uma política pública compensatória. Mas por que eu diria que o Bolsa-Família também tem um elemento estruturante? Porque certamente os filhos das famílias que recebem o Bolsa-Família não vão viver mais na condição em que os pais viveram, eles vão vier numa condição melhor, então tem um elemento estruturante. Então todas as políticas que são mais ou menos de longo prazo, que incidem para mudar de forma permanente a qualidade da sociedade têm uma dimensão estruturante. As outras, que são de mais curto prazo, são compensatórias. Uma outra divisão que se faz em relação às políticas públicas diz respeito se elas são universalistas ou focais.

Por exemplo, a política pública na qual vocês estão envolvidos é uma política focada, ela é focal, por quê? Porque ela atende um determinado público específico, enquanto, por exemplo, a ideia de que o direito à saúde deve ser para todos é uma política pública universal. Então existe também essa divisão. Então temos duas grandes divisões, ou ela é compensatória ou é estruturante, ou ela é universalista ou é focal. Então aqui temos as tipologias das políticas públicas. Bom, um outro elemento em relação às políticas públicas diz respeito a esse fato de que elas são um direito. E, normalmente, vejam o seguinte, existe duma subdivisão de direitos ao longo da história. Não sei se vocês conhecem um autor chamado Norberto Bobbio, foi um filósofo político italiano que morreu recentemente, ele tem um livro chamado A Era dos Direitos e nesse livro ele estabelece, mais ou menos, uns setenta direitos. Os direitos podem ser políticos, os que dizem respeito aos 
direitos de liberdade, eles podem ser direitos civis. E também citou na época os direitos políticos, que ele chamou de direitos de igualdade e assim por diante. E aí, a partir do século 20 surgem os direitos sociais.

Normalmente, a ideia de política pública se relaciona aos direitos sociais. E mais ultimamente surgiu uma outra classificação de direitos que diz respeito à ideia de direitos difusos. Direitos difusos ou direitos conexos e aí, por exemplo, temos toda a questão da política para as mulheres, as políticas ambientais, o direito de viver num mundo ambientalmente adequado, os próprios direitos LGBTT e assim por diante, que são chamados direitos difusos. Eu só queria ressaltar e enfatizar que as políticas públicas de um modo geral se referem a direitos sociais, embora elas possam se referir também a outros tipos de direitos. Como é que são garantidas as políticas públicas? Existem, basicamente, três formas de garantia das políticas públicas.

Em primeiro lugar, através de um auxílio pecuniário, quer dizer, a pessoa recebe monetariamente o recurso, por exemplo, aposentadoria. Ou outras formas que implicam no recebimento de um benefício pecuniário através de serviços, que me parece que é o caso de vocês, então o Estado mantém uma série de serviços ao portador de carecimento. E em terceiro lugar através da lei, por exemplo, a Lei Maria da Penha é uma política pública, quer dizer, a proteção das portadoras de carecimento, no caso, mulheres agredidas, se dá através do processo jurídico policial, digamos assim, então, na lei. Claro que normalmente todas as políticas públicas são vinculadas a leis, mas tem algumas políticas públicas que implicam só na lei, e a pessoa que sente a necessidade de fazer uso, demandar a proteção, ela recorre à lei, à autoridade, ou à autoridade policial ou à autoridade judiciária. Então, de modo geral, é através desses 3 elementos que são garantidas as políticas públicas.

Falado isso, eu queria falar rapidamente sobre o que é o Estado de direito. Vejam o seguinte, aqui tem toda uma história política por trás desse conceito de Estado de direito. Essa história do Estado de direito começa principalmente na Inglaterra, mais especificamente no século 17, quando aconteceu a Revolução Inglesa, quando em 1630, por ser uma guerra civil tendo de um lado o Parlamento e de outro lado a Monarquia dos Stuart. Aí o Parlamento derrubou a Monarquia, cortaram a cabeça do rei e tudo o mais, depois, em 1688, tivemos a chamada Revolução Gloriosa, quando o Parlamento coroou o rei. Então, nesses anos todos, surgiu uma série de debates na Inglaterra que estabeleceram mais ou menos o seguinte, vocês sabem que nos séculos 16 para 17 surgiram na Europa aquilo que se chamava as Monarquias Absolutistas. Eram monarquias que tinham o poder absoluto, o rei tinha o poder absoluto, tanto é que na França o famoso 
Luís XIV falou "o Estado sou eu”, quer dizer, ele era o poder, os reis tinham todo o poder, se dizia que os reis eram reis por direito divino e assim por diante.

O Estado de direito surge como um movimento para a limitação do poder do rei, então é essa a origem do conceito de Estado de direito. Estado de direito significa um poder limitado. E essa ideia do Estado de direito se vinculou depois, tanto na Inglaterra, mas principalmente nos Estados Unidos, quando eles proclamaram a independência e fizeram a sua constituição, à ideia de que o poder deveria ser constitucionalizado, não há um poder sem limite, não há um poder tirânico, onde a pessoa do poderoso decide o que fazer, mas deve seguir uma constituição. E essa constituição limita o poder do soberano, daquele que exerce o poder. Essa ideia foi muito trabalhada pelos federalistas norte-americanos, no contexto do surgimento da constituição norte-americana em 1786, e surgiu aquela que era uma ideia que não é nova, era uma ideia antiga, que já existia de certa forma na época da república romana antiga, a ideia da divisão do poder em três ramos.

Modernamente, o filósofo político Montesquieu elaborou essa ideia da divisão de poderes e depois ela foi bastante teorizada nos Estados Unidos. A ideia é de que existem três poderes, o poder executivo, o poder legislativo e o poder judiciário. E na teoria constitucional norte-americana se trabalhou muito a ideia de que deveria existir um equilíbrio e um controle desses poderes, um poder controlava o outro. O executivo é controlado pelo legislativo e judiciário, o executivo e o judiciário também controlam o legislativo e assim por diante. Então, a ideia de um equilíbrio e de um controle, aquilo que os norte- americanos chamam de freios, pesos e contrapesos, exatamente para limitar o poder. E por que Estado de direito? Porque a ideia do Estado de direito é que o poder tem um limite e esse limite são os direitos das pessoas. Quer dizer que quando você fala em Estado de direito, você está dizendo "olha, o poder tem um limite e esse limite são os direitos das pessoas”. Então aí temos os direitos fundamentais políticos e civis, que são os direitos de liberdade de organização, de expressão, de reunião de proteção e assim por diante. O Estado não pode violar esses direitos e se alguma autoridade do Estado viola esses direitos, ela é passível de punição. Então, provavelmente, ninguém de vocês aqui viveu na época da ditadura militar, quer dizer, teve todo um movimento político para a defesa do Estado de direito. O que significava? Que o Estado não podia chegar nas pessoas, cometer uma arbitrariedade, prendê-la indevidamente ou torturá-la e assim por diante. Então, essa era a luta pelo Estado de direito, quer dizer, quando você fala em Estado de direito, você está falando em direitos das pessoas. O Estado de direito implica também um outro conceito, que é o império da lei, ninguém está acima da lei. E implica 
também a noção do Estado republicano, que é aquela ideia da divisão do poder em três poderes. Então esse é o conceito básico do Estado dedireito.

E, finalmente, então vamos para essa temática do tema proposto, que são as Políticas Públicas no Contexto da Crise do Estado de Direito. Bom, vejam o seguinte, nós vivemos, evidentemente, um momento conjuntural de crise, com todo esse processo de impeachment da Dilma e a ascensão do governo Temer e por que se fala em crise do Estado de direito? Eu diria que se fala em crise do Estado de direito em três dimensões.

A primeira dimensão é porque as democracias, de um modo geral, pararam de funcionar, esse é o consenso entre os cientistas políticos, quer dizer, não é só a democracia brasileira que parou de funcionar, mas as democracias ocidentais em geral. E por que se diz que elas não funcionam? Em primeiro lugar, porque elas perderam a legitimidade. As pessoas não se reconhecem mais nessas democracias por aí, porque as democracias passaram por um processo de isolamento, de ilhamento e elas se colocam acima das pessoas, sem conseguir atender às demandas e os direitos das pessoas. Então existe o problema de crise das democracias.

Em segundo lugar, existe aquilo que alguns teóricos, particularmente, um filósofo italiano chamado Giorgio Agamben chama de Estado de exceção permanente. O que é o Estado de exceção permanente? Eu diria o seguinte, quer dizer, o judiciário não obedece mais a lei escrita estabelecida e ele cria uma legislação sem estar escrita, de forma permanente, porque ele age em cima dos fatos. Aqui no Brasil tem toda essa discussão em torno do procedimento da Lava-Jato, do que a Lava-Jato vem fazendo, por exemplo, as conduções coercitivas, a lei não permitiria, no entanto, quer dizer, o Juiz Moro cria uma legislação acima da Constituição e acima das leis. Esse processo do Estado de exceção, só para pontuar, rapidamente, surgiu nos Estados Unidos no contexto dos atentados de 11 de setembro, quando foram editados os chamados Atos Patrióticos, pelo Presidente Bush. Quer dizer, era uma legislação que violava os direitos das pessoas, consequentemente constituindo um Estado excepcional. Nesse Estado de exceção permanente, o juiz julga a partir dos fatos, ele cria uma lei não escrita a partir do fato. E essa era uma prática usada pelo regime nazista na Alemanha, que se chamava a Lei do Movimento, quer dizer, você na prática vai revogando a lei escrita e vai instituindo uma nova lei, a partir da decisão discricionária, arbitrária que o juiz toma em função do acontecimento, em função do fato. Quando acontece isso, todo mundo corre riscos, porque não vale mais a lei, não vale mais a Constituição e de certa forma passa a valer a vontade arbitrária do juiz. Então, esse é o segundo elemento da crise do Estado de direito. 
E o terceiro elemento da crise do Estado de direito, e esse é um problema que ocorre, fundamentalmente, no Brasil hoje, embora aconteça também em outros países da América Latina, diz respeito a esse movimento que o governo Temer está instituindo no Brasil, que é um movimento de confrontação aquilo que eu chamo do espírito da Constituição de 1988. Vocês sabem que a Constituição de 1988 foi definida pelo Ulisses Guimarães como a constituição cidadã. Ela é uma constituição que visa criar uma espécie de um colchão de segurança social, de seguridade social, de segurança social das pessoas, portanto essa segurança social seguia garantida por políticas públicas. E essa emenda chamada PEC 241, ou PEC 55 agora no Senado, ataca exatamente esse espírito da Constituição de 1988. E eu entendo que isso é extremamente grave, porque um governo que nasce, do meu ponto de vista, de uma ilegitimidade, porque por pior, por ruim que fosse o governo Dilma, o fato é que eu entendo que não havia elementos legais para fazer o impeachment. Nesse sentido, ao menos é a minha opinião, o que houve no Brasil foi um golpe. E as gravações mostram ali, várias gravações, principalmente as do Sérgio Machado, que houve toda uma articulação de setores do PMDB, particularmente, para fazer o golpe, para acontecer isso que vocês estão vendo que está acontecendo agora. Quer dizer, uma tentativa de barrar a Lava-Jato. As gravações do Sérgio Machado, que era diretor da Transpetro mostram claramente isso, que o objetivo era parar a Lava-Jato. E agora, vocês veem todas essas manobras que estão acontecendo no Congresso, confirmando que aquelas gravações eram verdadeiras e que uma das intenções principais era exatamente barrar a Lava-Jato para salvar o pescoço de centenas de políticos.

Bom, vocês poderiam me perguntar o seguinte, dizer, como o governo Dilma estava ruim, a Dilma não conseguia governar e assim por diante, teria alguma outra saída que não fosse o impeachment? Eu diria que teria, eu apontaria duas saídas. Em primeiro lugar, um pacto de todas as forças políticas tentando garantir uma governabilidade mínima para a Dilma, para que ela chegasse a 2018 e a segunda alternativa era uma renúncia, e aí eu acho que todos os partidos erraram, inclusive o PT e inclusive a Dilma e assim por diante, seria uma renúncia da Dilma e do Temer, uma renúncia conjunta e isso provocaria uma nova eleição presidencial automaticamente, sem passar por emenda constitucional e assim por diante. Ninguém propôs isso aí, então havia, existiam saídas melhores. Bom, então temos esse governo, que é fruto de uma ilegitimidade e um governo que ataca as políticas públicas e vocês, provavelmente, eu não sei, especificamente, a situação de vocês, mas, provavelmente, vocês já estão sofrendo os efeitos desses ataques à política pública que vocês estão levando adiante. Quer dizer, esse é um ataque generalizado, toda a área social, pública vai sofrer se essa PEC for aprovada em definitivo e nesse sentido 
nós teremos, inequivocamente, um retrocesso social no Brasil. Teremos um retrocesso histórico de grandes proporções, e aquilo que nós vínhamos construindo nos últimos 30, 40 anos vai retroceder terrivelmente e vão ser demandadas várias lutas para que depois haja uma recuperação.

Como enfrentar esse processo da confrontação do espírito da Constituição cidadã e da ideia da constituição de um mínimo bem-estar social no país? Eu entendo que é através da luta e da organização, não tem outro jeito, porque eu entendo que esse congresso que está aí é um congresso pior, um dos piores congressos da nossa história, é um congresso conservador, um congresso antissocial, um congresso que se importa apenas com interesses de grupos particulares. E não vai ser esse congresso que vai, digamos assim, salvar as políticas públicas. Vocês veem, por exemplo, mesmo nessa questão do aborto, o Supremo Tribunal Federal entendeu o que é o direito do aborto e agora o Presidente da Câmara, o Rodrigo Maia desencavou um projeto de lei para proibir o aborto. Então, tanto no campo dos costumes, quanto no campo das políticas públicas, das políticas sociais e assim por diante nós estamos caminhando, inequivocamente, para um retrocesso. Bom, os partidos de esquerda estão fragilizados, o próprio PT está desmoralizado perante a opinião pública, então, do ponto de vista dos partidos, nós temos pouca capacidade de reação, a sociedade tem pouca capacidade de reação. E qual é o outro risco? O outro risco que eu entendo é que cada movimento social vá lutar pelo seu interesse particular. Quer dizer, se não houver uma união dos movimentos sociais, o rolo compressor vai passar, porque um movimento social lutando isoladamente, separadamente, tem pouca força. Então eu entendo que deveria haver uma união dos movimentos sociais, uma união com o que restou dos partidos progressistas para fazer frente a esse rolo compressor da desconstituição das políticas públicas, da desconstituição das políticas sociais no Brasil. Isso é muito difícil, tanto aqui no Brasil quanto, principalmente, porque há um contexto internacional extremamente conservador. Pelo que nós vimos nos Estados Unidos, pelo que vai acontecer na Europa, provavelmente, uma vitória de partidos de extrema direita e antissociais, anti civilizatórios, eu diria. A própria questão ambiental, vocês veem aí que o Trump está confrontando a própria política ambiental, o que é um grande risco para toda a humanidade. Então, digamos assim, esse é o problema.

Então, a única coisa que eu poderia dizer é que não há saída a não ser lutar. Não há saída a não ser a mobilização, porque nós temos que acreditar em nós mesmos, porque o sistema político está falido, está corrompido, os partidos não têm credibilidade. Para vocês terem uma ideia, uma pesquisa recente mostra que os partidos políticos têm apenas $7 \%$ de apoio positivo, uma pesquisa sobre a própria democracia mostra que a 
maioria da sociedade brasileira prefere um regime de força, um regime ditatorial, então a própria democracia corre riscos nesse sentido. Então a única recomendação que eu tenho para vocês é o seguinte: se mobilizem, se organizem e lutem. Eu não vejo outra saída neste momento. Era isso o que eu queria dizer para vocês e vamos tentar fazer um debate para falar de outras questões que ficaram fora desse contexto da exposição.

Muito obrigado. 